Article

\title{
Highly Dispersed Pt Nanoparticles on N-Doped Ordered Mesoporous Carbon as Effective Catalysts for Selective Hydrogenation of Nitroarenes
}

\author{
Yao Sheng ${ }^{1} \mathbb{1}$, Xinrui Lin ${ }^{1}$, Xueguang Wang ${ }^{1, *}$, Xiujing Zou ${ }^{1}$ and Chunlei Zhang ${ }^{2, *}$ \\ 1 State Key Laboratory of Advanced Special Steel, School of Materials Science and Engineering, \\ Shanghai University, 99 Shangda Road, BaoShan District, Shanghai 200444, China; \\ shengyao@shu.edu.cn (Y.S.); linxinrui1997@163.com (X.L.); xjzou@shu.edu.cn (X.Z.) \\ 2 Education Ministry Key Lab of Resource Chemistry, Shanghai Key Laboratory of Rare Earth Functional \\ Materials, College of Chemistry and Materials Science, Shanghai Normal University, 100 Guilin Road, \\ XuHui District, Shanghai 200234, China \\ * Correspondence: wxg228@shu.edu.cn (X.W.); zhangchunlei@shnu.edu.cn (C.Z.)
}

Received: 5 March 2020; Accepted: 23 March 2020; Published: 31 March 2020

\begin{abstract}
Highly-dispersed Pt nanoparticles supported on nitrogen-modified CMK-3 mesoporous carbon (Pt/N-CMK-3) were first fabricated by a two-step impregnation route. The influences of $\mathrm{N}$ content on the catalyst porous structure, Pt nanoparticle size, surface properties, and interaction between $\mathrm{Pt}$ species and the support were investigated in detail using $\mathrm{N}_{2}$ sorption, $\mathrm{X}$-ray diffraction (XRD), transmission electron microscopy (TEM), and X-ray photoelectron spectra (XPS). The $\mathrm{N}$ species acted as anchoring sites for the stabilization of Pt particles. Benefiting from the formation of ultrafine metal nanoparticles, the Pt/N-CMK-3 exhibited excellent catalytic activity and selectivity for the selective hydrogenation of nitro aromatics to the corresponding anilines with hydrogen. The $\mathrm{Pt} / \mathrm{N}-\mathrm{CMK}-3$ catalyst could be reused eight times and keep its catalytic performance.
\end{abstract}

Keywords: heterogeneous catalysis; Pt nanoparticles; N-doped carbon; nitroarenes hydrogenation

\section{Introduction}

Substituted aromatic amines are crucial industrial intermediates for the production of various fine chemicals, such as dyestuffs, agrochemicals, pharmaceuticals, and polymers, and most of them are synthesized by catalytic reduction of corresponding nitro aromatics [1-3]. Particularly, sheterogeneous catalytic reduction over supported metal catalysts as an environment-friendly and efficient protocol attracts much interest $[4,5]$. The selective reduction of nitro aromatics over supported metal catalysts was widely adopted with different hydrogen sources, such as hydrazine hydrate, sodium borohydride, gas hydrogen, formic acid, ammonia borane, and so on [6-9]. Among them, $\mathrm{H}_{2}$, a low cost, non-toxic, and the cleanest hydrogen donor, is recognized as the most ideal reducing agent for the hydrogenation of nitro aromatic compounds in industrial production.

Heterogeneous noble metal-based catalysts such as $\mathrm{Ru}, \mathrm{Rh}, \mathrm{Pt}$, and $\mathrm{Pd}$ have been reported to be efficient for the hydrogenation of nitroarenes $[10,11]$. Downsizing the noble metal particles to a few nanometers can dramatically improve their catalytic activity, due to the increasing surface-to-atom ratio $[12,13]$. However, the supported small metal nanoparticles often suffer from serious aggregation because of the high surface energy [14-16]. In addition, it remains challenging to keep other reducible groups, especially the halogen groups $(\mathrm{F}, \mathrm{Cl}, \mathrm{Br}$, and $\mathrm{I})$, intact at high conversion rates when using noble metal catalysts with $\mathrm{H}_{2}$ as the hydrogen source [17-19]. Generally, the catalytic performance is closely linked to the metal particle sizes, the structure or surface properties of the support, and the interaction effect between the metal and support. The activity and selectivity of the catalyst for 
the hydrogenation of nitroarenes could be modified by preparation method, thermal treatment, and element doping [20-22].

Mesoporous materials are considered as the ideal choices as catalyst supports due to their large surface areas, tunable pore size, and thermal and chemical stability [23-25]. Particularly, functionalized supports, such as nitrogen doped mesoporous carbon, have received great interest because the incorporation of $\mathrm{N}$ atoms into mesoporous carbon frameworks not only alters the mechanical and electronic properties, and the surface chemical states, of carbon materials, but also is efficient for the stabilization of the metal nanoparticle [26,27].

In the present work, we report for the first time an $\mathrm{N}$-doped ordered mesoporous carbon fabricated by using a simple impregnation step with 2-methylimidazole as an ideal nitrogen source (N-CMK-3-x, where $x$ represents the 2 -methylimidazole amount). The $\mathrm{N}-\mathrm{CMK}-3$ supports act as efficient catalytic supports to disperse and stabilize ultrafine Pt nanoparticles. The as-prepared Pt/N-CMK-3 catalysts exhibited highly efficient catalytic activity and chemoselectivity for the hydrogenation of nitro aromatics into corresponding anilines with $\mathrm{H}_{2}$ under room temperature. Of particular importance, was that the $\mathrm{Pt} / \mathrm{N}-\mathrm{CMK}-3$ was rather stable without any leaching of metal nanoparticles and could be reused for the selective hydrogenation of nitrobenzene.

\section{Results and Discussion}

\subsection{Catalyst Characterization}

$\mathrm{N}_{2}$ adsorption-desorption isotherms and corresponding pore size distribution profiles of the CMK-3, Pt/CMK-3, and Pt/N-CMK-3-x samples were recorded. As depicted in Figure $1 \mathrm{a}$, all of the $\mathrm{Pt} / \mathrm{N}-\mathrm{CMK}-3-\mathrm{x}$ samples exhibited typical IV isotherms with distinct hysteresis at relative higher pressure $\left(\mathrm{P} / \mathrm{P}_{0}>0.4\right)$, ascribing to the characteristics of mesoporous structure, similar to that of the CMK-3 support. This result demonstrated that the mesoporous structure of CMK-3 was still kept after being incorporated with $\mathrm{Pt}, \mathrm{C}$, and $\mathrm{N}$ components. The similar pore size distributions of the samples in Figure $1 \mathrm{~b}$ also proved this point, and the pore sizes were primarily in the range of $3-4 \mathrm{~nm}$. The detailed textural parameters and physical properties of the samples are shown in Table 1. With the increased amount of 2-methylimidazole, the specific surface area, pore volume, and pore size of the $\mathrm{Pt} / \mathrm{N}-\mathrm{CMK}-3-\mathrm{x}$ showed a remarkable decline, implying the successful incorporation of $\mathrm{C}$ and $\mathrm{N}$ from the pyrolysis of 2-methylimidazole. The final contents of $\mathrm{Pt}$ and $\mathrm{N}$ in the samples were determined by inductively coupled plasma atomic emission spectroscopy (ICP-AES) and CHN elemental analyzer (Table 1). As can be seen, the Pt contents were all located at $1.90 \pm 0.05 \mathrm{wt} \%$, while the $\mathrm{N}$ contents showed obvious increase from 2.1 to $3.5 \mathrm{wt} \%$ with increasing the amount of 2-methylimidazole. However, when the amount of 2-methylimidazole was continuously increased, the Pt/N-CMK-3-3 showed only a small increase in $\mathrm{N}$ contents about $0.2 \mathrm{wt} \%$. Maybe the excess 2-methylimidazole did not incorporate in the CMK-3 frameworks, due to $\mathrm{N}$ loss during the synthesis at $800{ }^{\circ} \mathrm{C}$.

Table 1. Pt and N contents, and physical properties of prepared materials.

\begin{tabular}{|c|c|c|c|c|c|c|}
\hline Samples & $\operatorname{Pt}(w t \%)$ & N (wt \%) & $\begin{array}{l}\text { Specific Surface } \\
\text { Area }\left(\mathrm{m}^{2} \mathrm{~g}^{-1}\right)\end{array}$ & $\begin{array}{l}\text { Pore Volume } \\
\left(\mathrm{cm}^{3} \mathrm{~g}^{-1}\right)\end{array}$ & $\begin{array}{l}\text { Pore Size } \\
\quad(\mathrm{nm})\end{array}$ & $\begin{array}{l}\text { Pt crystallite Size } \\
\text { by XRD }(\mathrm{nm})\end{array}$ \\
\hline CMK-3 & - & - & 979 & 1.02 & 3.9 & - \\
\hline $\mathrm{Pt} / \mathrm{CMK}-3$ & 1.95 & - & 971 & 1.02 & 3.9 & 5.5 \\
\hline $\mathrm{Pt} / \mathrm{N}-\mathrm{CMK}-3-1$ & 1.92 & 2.1 & 620 & 0.60 & 3.7 & 3.0 \\
\hline $\mathrm{Pt} / \mathrm{N}-\mathrm{CMK}-3-2$ & 1.89 & 3.5 & 590 & 0.52 & 3.5 & - \\
\hline $\mathrm{Pt} / \mathrm{N}-\mathrm{CMK}-3-3$ & 1.87 & 3.7 & 548 & 0.49 & 3.4 & - \\
\hline Spent Pt/N-CMK-3-2 & 1.86 & 3.5 & 579 & 0.51 & 3.5 & - \\
\hline
\end{tabular}



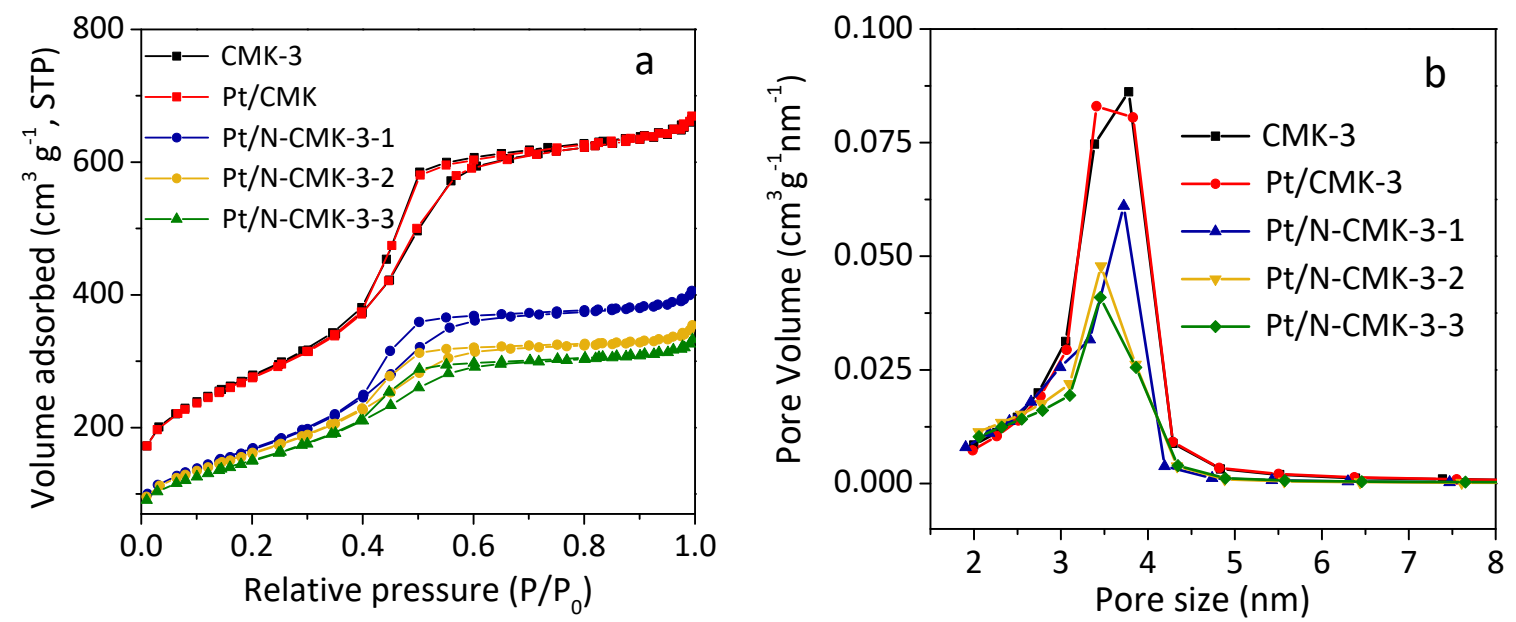

Figure 1. (a) $\mathrm{N}_{2}$ sorption isotherms and (b) pore size distributions of the CMK-3, Pt/CMK-3, and $\mathrm{Pt} / \mathrm{N}-\mathrm{CMK}-3-\mathrm{x}(\mathrm{x}=1,2$, and 3$)$ samples.

The XRD patterns of the CMK-3 and Pt/N-CMK-3 materials are displayed in Figure 2. All samples showed broadened diffraction peaks at $2 \theta=43^{\circ}$, indicating the presence of graphitic carbon. For the $\mathrm{Pt} / \mathrm{CMK}-3$ catalyst, an obvious diffraction peak at $2 \theta=39.8^{\circ}$ was assigned to (111) lattice planes of metal $\mathrm{Pt}$ (PDF 70-2431). When the $\mathrm{N}$ species were incorporated in the matrix, the diffraction peak for metal $\mathrm{Pt}$ became weak and wide. As the $\mathrm{N}$ content was further increased, the diffraction peak of $\mathrm{Pt}$ (111) in Pt/N-CMK-3-2 and Pt/N-CMK-3-3 was disappeared completely, indicating that the Pt species were highly dispersed in the N-CMK-3 matrix. These results revealed that the incorporation of $\mathrm{N}$ in the carbon matrix benefited the dispersion of Pt nanoparticles on the surface, due to the complexing and stabilizing effect.

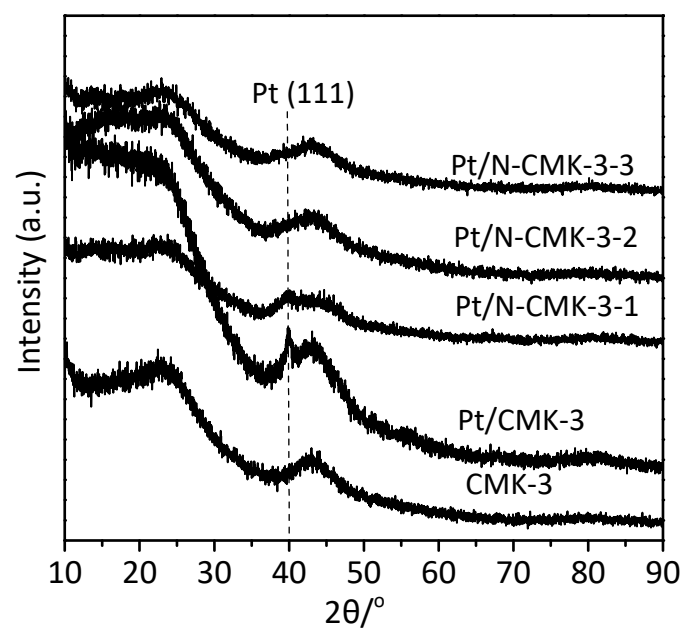

Figure 2. XRD patterns of the CMK-3, Pt/CMK-3, and Pt/N-CMK-3-x ( $x=1,2$, and 3$)$ samples.

Figure 3 presents the representative TEM images of the Pt/CMK-3 and Pt/N-CMK-3-x samples. All the samples displayed obvious order pore channels, similar to pure CMK-3 (not shown). For $\mathrm{Pt} / \mathrm{CMK}-3$, plenty of darker metal nanoparticles with average particle sizes of $5.5 \mathrm{~nm}$ were distributed on the support. As the $\mathrm{N}$ species were introduced, the average size of Pt nanoparticles was remarkably decreased to $2.9 \mathrm{~nm}$ in Pt/N-CMK-3-1, which was attributed to the significant role of $\mathrm{N}$ in anchoring metal particles. It can be seen from Table 1 that the Pt particle sizes of Pt/N-CMK-3 and Pt/N-CMK-3-1 counted by TEM were approximately equal to the mean sizes of Pt crystallites by XRD. When the N contents were continuously increased, the mean sizes of the Pt particles reached a minimum value of about $1.2 \mathrm{~nm}$ in Pt/N-CMK-3-2 catalyst. These results, in agreement with the XRD result in Figure 2, 
confirmed that the $\mathrm{N}$ content had significant effects on the sizes of metal Pt crystallites or particles formed, which will be analyzed in detail in subsequent XPS analysis. In addition, the high-angle annular dark-field scanning TEM (HAADF-STEM) and the elemental mapping images demonstrated that $\mathrm{Pt}$ and $\mathrm{N}$ species were uniformly dispersed in $\mathrm{Pt} / \mathrm{N}-\mathrm{CMK}-3-2$ (Figure $3 \mathrm{e}$ ).
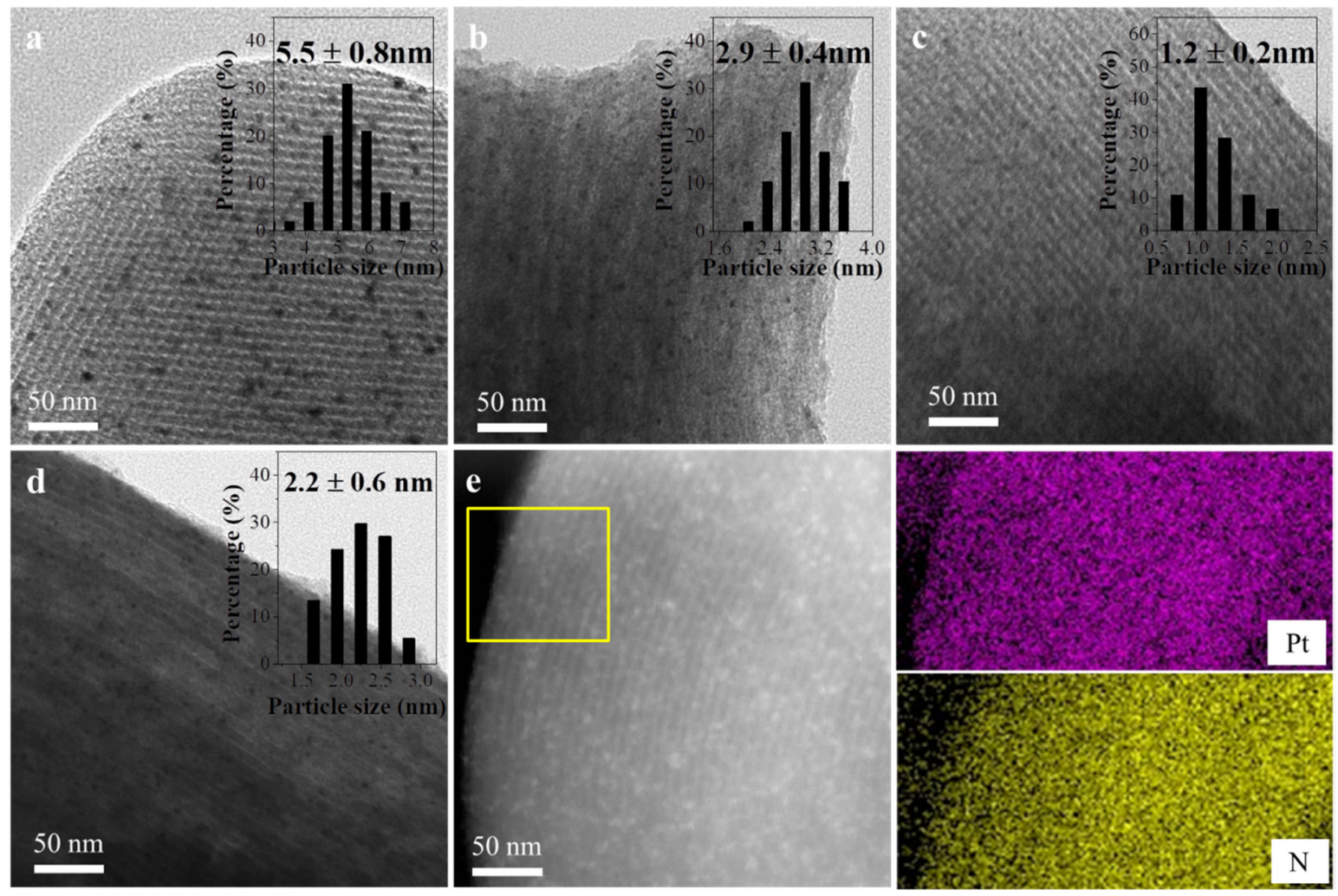

Figure 3. TEM images of (a) Pt/CMK-3, (b) Pt/N-CMK-3-1, (c) Pt/N-CMK-3-2, (d) Pt/N-CMK-3-3, and (e) high-angle annular dark-field scanning-transmission electron microscopy (HAADF-STEM) and elemental mapping images of Pt/N-CMK-3-2. The average diameters of the Pt particles were obtained by measuring about 200 clusters for each sample.

The valence states of Pt and $\mathrm{N}$ types of the prepared materials were characterized by XPS spectra. As depicted in Figure 4a, the Pt 4f XPS spectra of Pt/CMK-3 showed symmetric doublet peaks at the binding energy of 71.7 and $75.2 \mathrm{eV}$, respectively, which were attributed to $\mathrm{Pt}^{0}$. However, this binding energy value was higher than the binding energy of bulk $\mathrm{Pt}\left(4 \mathrm{f}_{7 / 2}=71.2 \mathrm{eV}\right)$ [28-30], indicating the interaction between Pt particles and the CMK-3. When the CMK-3 support was treated with 2-methylimidazole and the $\mathrm{N}$ species were introduced into the matrix, the binding energies of $\mathrm{Pt}^{0}$ $4 \mathrm{f}$ were shifted to higher values with increasing $\mathrm{N}$ content, implying the existence of an interaction effect between Pt and $\mathrm{N}$ species due to a charge-transfer. The $\mathrm{N}$ species in the Pt/N-CMK-3-2 was further identified by the N 1s XPS spectrum in Figure 4b. Three peaks at 397.5, 399.4, and $400.7 \mathrm{eV}$ were assigned to pyridinic-type, pyrrolic-type, and graphitic-type $\mathrm{N}$ [31-34], respectively. It has been reported that the pyrrolic and pyridinic $\mathrm{N}$ sites act as anchoring sites for the stabilization of $\mathrm{Pt}$ particles and suppressing their agglomeration $[35,36]$. The relative peak area percentage of each type of $\mathrm{N}$ in $\mathrm{Pt} / \mathrm{N}-\mathrm{CMK}-3-\mathrm{x}$ catalysts is listed in Table 2 . The surface $\mathrm{N}$ compositions were close to those determined by the $\mathrm{CHN}$ elemental analyzer in Table 1 . When the $\mathrm{N}$ content was increased, the relative peak intensity for graphitic $\mathrm{N}$ was strengthened, and in the meanwhile, the relative peak intensity for pyrrolic $\mathrm{N}$ was found to be decreased. However, the peak intensities for the pyridinic $\mathrm{N}$ showed no obvious change. Therefore, the total content of pyrrolic and pyridinic $\mathrm{N}$ for the $\mathrm{Pt} / \mathrm{N}-\mathrm{CMK}-3-2$ showed a maximum value, due to the combination of the two factors of the increases in $\mathrm{N}$ contents and the decrease in pyrrolic $\mathrm{N}$ on the catalyst surfaces. 

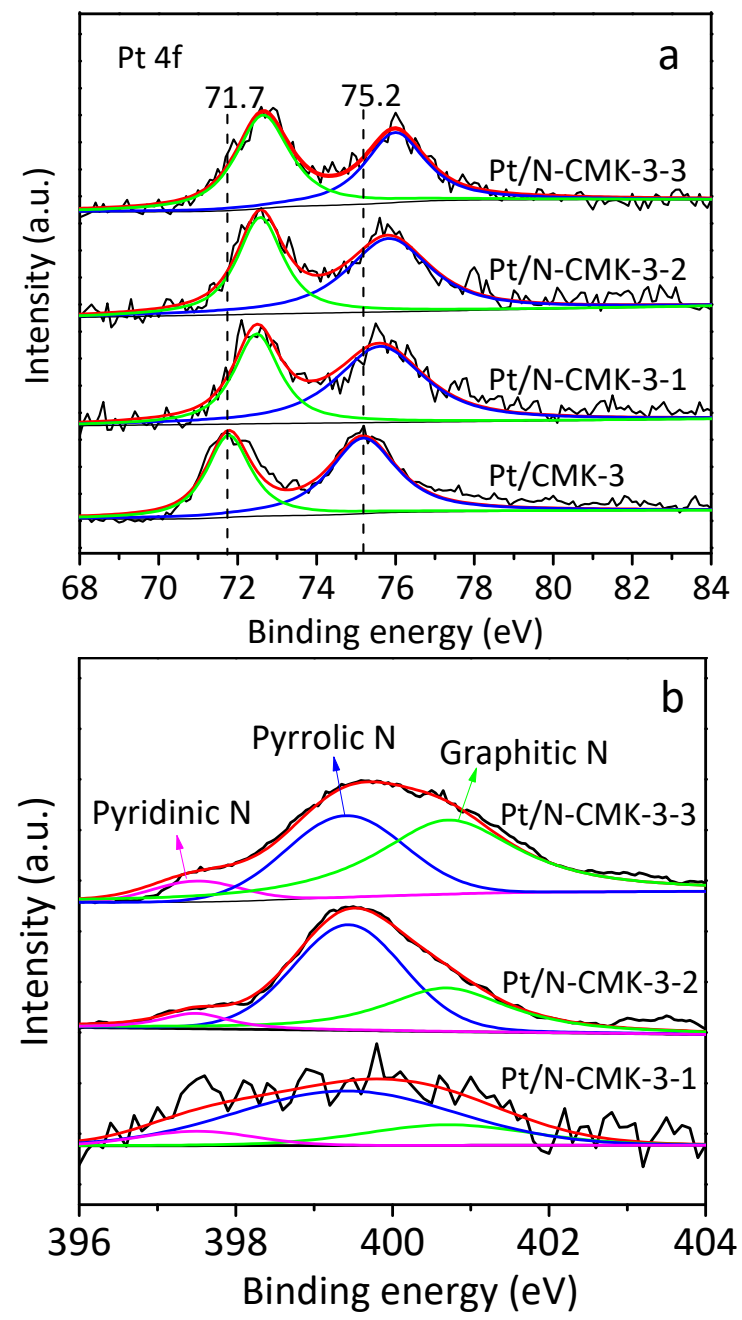

Figure 4. (a) Pt $4 \mathrm{f}$ XPS spectra of Pt/CMK-3 and Pt/N-CMK-3-x ( $x=1,2$, and 3) and (b) N 1s XPS spectra of Pt/N-CMK-3-x $(x=1,2$, and 3).

Table 2. Relative peak area percentage of each type of $\mathrm{N}$ in Pt/N-CMK-3-x catalysts.

\begin{tabular}{ccccc}
\hline Samples & $\begin{array}{c}\text { Nitrogen Content } \\
\text { (Atom \%) }\end{array}$ & $\begin{array}{c}\text { Pyridinic-Type (\%) } \\
\mathbf{b}\end{array}$ & $\begin{array}{c}\text { Pyrrolic-Type (\%) } \\
\mathbf{b}\end{array}$ & $\begin{array}{c}\text { Graphitic-Type } \\
\mathbf{( \% )} \mathbf{b}^{\mathbf{b}}\end{array}$ \\
\hline Pt/N-CMK-3-1 & 2.0 & 9.0 & 68.2 & 22.8 \\
Pt/N-CMK-3-2 & 3.3 & 6.9 & 57.6 & 35.5 \\
Pt/N-CMK-3-3 & 3.6 & 7.0 & 41.9 & 51.1 \\
\hline
\end{tabular}

${ }^{a}$ The $\mathrm{N}$ content was determined by XPS. ${ }^{\mathrm{b}}$ Data are the percentage of the peak area of the fitted nitrogen in the total area of the $\mathrm{N} 1$ s peak.

\subsection{Catalytic Reaction}

Nitrobenzene was first conducted as a model compound over the Pt/N-CMK-3-2 to optimize the reaction conditions, and the results are listed in Table 3. Firstly, the hydrogenation of nitrobenzene with $\mathrm{H}_{2}$ was investigated in different solvents. All the solvents like ethylacetate, toluene, ethyl ether, methanol, and ethanol showed excellent catalytic activity, but ethanol (nitrobenzene/ethanol = 4:1 $\left(\mathrm{mmol} \mathrm{mL} \mathrm{L}^{-1}\right)$ ) gave the highest nitrobenzene conversion (entries 1-7). Secondly, the results showed that the nitrobenzene conversion steadily increased with increasing $\mathrm{H}_{2}$ pressure from 0.5 to $2 \mathrm{MPa}$, indicated that the $\mathrm{H}_{2}$ pressure influenced the dissolution of $\mathrm{H}_{2}$ in the solvent. The reaction rate did not change obviously when increasing $\mathrm{H}_{2}$ pressure from 2 to $6 \mathrm{MPa}$ (entry 5 and entries 10,11), implying 
the absence of a hydrogen transport limitation at high pressure. Finally, the nitrobenzene conversion continually increased with the temperature without loss of selectivity (100\%) (entries 12-14).

Table 3. Catalytic performance of Pt/N-CMK-3-2 catalysts for hydrogenation of nitrobenzene ${ }^{\mathrm{a}}$.

\begin{tabular}{|c|c|c|c|c|c|}
\hline Entry & Solvent (mL) & $\begin{array}{c}\mathrm{H}_{2} \text { Pressure } \\
\text { (MPa) }\end{array}$ & $\begin{array}{c}\text { Temperature } \\
\left({ }^{\circ} \mathrm{C}\right)\end{array}$ & Conv. $(\%)^{b}$ & Sel. (\%) \\
\hline 1 & Ethylacetate $(20 \mathrm{~mL})$ & 2 & 40 & 49.2 & 100 \\
\hline 2 & Toluene $(20 \mathrm{~mL})$ & 2 & 40 & 25.2 & 100 \\
\hline 3 & Ethyl ether (20 mL) & 2 & 40 & 44.3 & 100 \\
\hline 4 & Methanol (20 mL) & 2 & 40 & 53.7 & 100 \\
\hline 5 & Ethanol (20 mL) & 2 & 40 & 79.5 & 100 \\
\hline 6 & Ethanol (10 mL) & 2 & 40 & 65.1 & 100 \\
\hline 7 & Ethanol (30 mL) & 2 & 40 & 63.6 & 100 \\
\hline 8 & Ethanol (20 mL) & 0.5 & 40 & 24.4 & 100 \\
\hline 9 & Ethanol (20 mL) & 1 & 40 & 56.8 & 100 \\
\hline 10 & Ethanol (20 mL) & 4 & 40 & 80.3 & 100 \\
\hline 11 & Ethanol $(20 \mathrm{~mL})$ & 6 & 40 & 81.4 & 100 \\
\hline 12 & Ethanol (20 mL) & 2 & 60 & 98.2 & 100 \\
\hline 13 & Ethanol (20 mL) & 2 & 80 & $100(0.5 \mathrm{~h})$ & 100 \\
\hline 14 & Ethanol (20 mL) & 2 & 100 & $100(0.2 \mathrm{~h})$ & 100 \\
\hline
\end{tabular}

${ }^{a}$ Reaction conditions: $80 \mathrm{mmol}$ nitrobenzene, $40 \mathrm{mg}$ catalyst, $1.0 \mathrm{~h} .{ }^{\mathrm{b}}$ Actual required reaction time for full conversion of nitrobenzene in parenthesis.

We compared the initial conversions of nitrobenzene as a model compound over Pt/N-CMK-3-x catalysts with $\mathrm{H}_{2}$ in ethanol for $10 \mathrm{~min}$ at $40{ }^{\circ} \mathrm{C}$, and the results are summarized in Table 4 . As can be seen, the CMK-3 and N-CMK-3-2 materials provided no activity (entries 1 and 2). When the CMK-3 was treated with 2-methylimidazole, the $\mathrm{Pt} / \mathrm{N}-\mathrm{CMK}-3-1$ showed a nitrobenzene conversion of $8.0 \%$, which was much higher than that of Pt/CMK-3 (3.9\%). The Pt/N-CMK-3-2 with the minimum particle size showed the highest nitrobenzene conversion. The turnover frequencies (TOFs) for the Pt/N-CMK-3-2 exhibited high values of $18,819 \mathrm{~h}^{-1}$. However, when the $\mathrm{N}$ content was further increased, the initial conversions of nitrobenzene of $\mathrm{Pt} / \mathrm{N}-\mathrm{CMK}-3-3$ showed a decline. These variations matched well with the results of TEM. These results demonstrated that the activity of the Pt/N-CMK-3-x for the selective hydrogenation of nitrobenzene was significantly influenced by the $\mathrm{N}$ content inducing changes in the size of the Pt nanoparticles.

The scope of Pt/N-CMK-3-2 in hydrogenation of nitroarenes, a series of nitro compounds with diverse substituent groups, were tested under the optimized reaction conditions, and the results are summarized in Table 5. To our great delight, the Pt/N-CMK-3-2 exhibited high activity and selectivity for the hydrogenation of substituted nitroarenes. Apart from nitrobenzene (Table 5, entry 1), the substituted nitrobenzenes having nonreducible groups like $-\mathrm{CH}_{3},-\mathrm{NH}_{2}$, and $\mathrm{CH}_{3} \mathrm{O}$ - were also furnished with excellent yield (>99\%) (entries 2-7). It has been reported that supported noble catalysts, such as $\mathrm{Pt}, \mathrm{Pd}$, Rh, etc., display poor chemoselectivity to the hydrogenation of the nitro group when halogen groups exist in the same molecule [37]. Herein, no obvious dehalogenation product was observed in the selective hydrogenation of the halogen-substituted nitroarenes (entries 8-13). Moreover, other reducible groups such as $-\mathrm{COOCH}_{2} \mathrm{CH}_{3},-\mathrm{COOH},-\mathrm{CN}$, and $-\mathrm{CHO}$ on the nitrobenzene were also well tolerated to give the corresponding amines in high selectivity (entries 14-17). Also, for heterocyclic nitroarenes containing N element, full conversion and high selectivity of $>99.0 \%$ was achieved (entries 19-22). In contrast, the hydrogenation of $p$-chloronitrobenzene over Pt/CMK-3 showed not only low catalytic activity but also poor selectivity (entry 23). The high chemoselectivity of the Pt/N-CMK-3-2 catalysts for the hydrogenation of nitroarenes to anilines was likely due to the higher reactivity of nitro group than other functional groups. 
Table 4. Catalytic hydrogenation of nitrobenzene over different catalysts ${ }^{a}$.

\begin{tabular}{ccccc}
\hline Entry & Catalyst & Conv. (\%) & TOF $\left.\mathbf{( h}^{-\mathbf{1}}\right)^{\mathbf{b}}$ & Sel. (\%) \\
\hline 1 & CMK-3 & 0 & 0 & - \\
2 & N-CMK-3-2 & 0 & 0 & - \\
3 & Pt/CMK-3 & 3.9 & 4680 & 100 \\
4 & Pt/N-CMK-3-1 & 8.0 & 9750 & 100 \\
5 & Pt/N-CMK-3-2 & 15.2 & 18819 & 100 \\
6 & Pt/N-CMK-3-3 & 9.4 & 11763 & 100 \\
\hline
\end{tabular}

a Reaction conditions: $80 \mathrm{mmol}$ nitrobenzene, $40 \mathrm{mg}$ catalyst, $20 \mathrm{~mL}$ of ethanol, $40{ }^{\circ} \mathrm{C}, 2 \mathrm{MPa} \mathrm{H}_{2}, 10 \mathrm{~min} .{ }^{\mathrm{b}}$ The number of moles of converted nitrobenzene per Pt mole per hour based on the total Pt by ICP in Table 1.

The stability and reusability of the $\mathrm{Pt} / \mathrm{N}-\mathrm{CMK}-3-2$ catalyst were further investigated by the hydrogenation of nitrobenzene at $40{ }^{\circ} \mathrm{C}$. As presented in Figure 5, the Pt/N-CMK-3-2 exhibited a nitrobenzene conversion of $80.1 \%$ in the first cycle. After completion of the reaction, the catalyst was separated by filtration, washed with ethanol three times, and dried overnight at $60^{\circ} \mathrm{C}$. Then the recovered catalyst was directly used for the next run without any reactivation or purification. The nitrobenzene conversion remained at $78.7 \%$ for the eight runs, and the aniline selectivity was kept at $100 \%$. After each cycling reaction, the Pt contents in the product solution were determined by ICP-AES. It was found that the solution hardly contained the Pt element ( $<1 \mathrm{ppm})$. As can be seen in Table 1 , the total Pt content in the spent $\mathrm{Pt} / \mathrm{N}-\mathrm{CMK}-3-2$ was $1.86 \mathrm{wt} \%$, which was very close to that of before the reaction. It was demonstrated that the $\mathrm{Pt} / \mathrm{N}-\mathrm{CMK}-3-2$ possessed good recyclability and has great potential for practical applications in the selective hydrogenation of nitroarenes in the future.

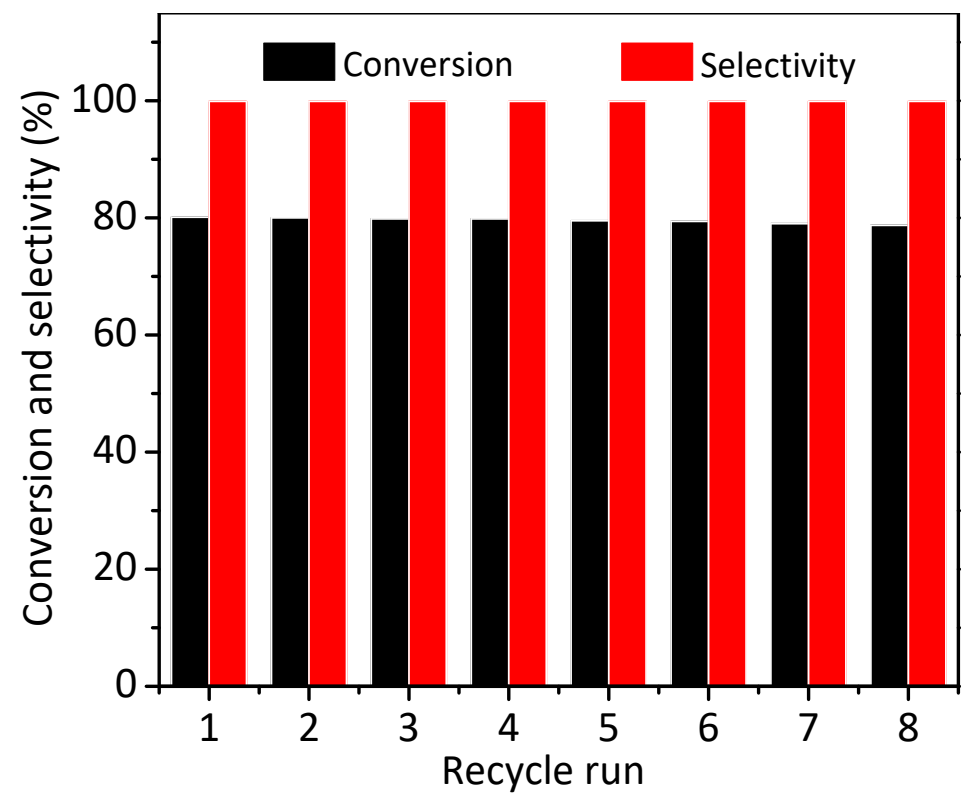

Figure 5. Reuse tests of the Pt/N-CMK-3-2 catalyst. Reaction conditions: $80 \mathrm{mmol}$ nitrobenzene, $40 \mathrm{mg}$ catalyst, $20 \mathrm{~mL}$ of ethanol, $40{ }^{\circ} \mathrm{C}, 2 \mathrm{MPa} \mathrm{H}_{2}, 1.0 \mathrm{~h}$. 
Table 5. Chemoselective hydrogenation of various substituted nitroarenes catalyzed by $\mathrm{Pt} / \mathrm{N}-\mathrm{CMK}-3-2$ catalyst ${ }^{\mathrm{a}}$.

\begin{tabular}{llll} 
& Time (h) & Conv. (\%) & Sel. (\%) \\
\hline & & $>99.9$ & \\
\hline
\end{tabular}

a Reaction conditions: $80 \mathrm{mmol}$ substrate, $40 \mathrm{mg}$ catalyst, $20 \mathrm{~mL}$ of ethanol, $40{ }^{\circ} \mathrm{C}, 2 \mathrm{MPa} \mathrm{H}_{2} \cdot{ }^{\mathrm{b}}$ Performed over $\mathrm{Pt} / \mathrm{CMK}-3$. 


\section{Experimental Section}

\subsection{Chemicals}

All chemicals were purchased and used without further purification. Pluronic P123 $\left(\mathrm{EO}_{20} \mathrm{PO}_{70} \mathrm{EO}_{20}\right)$ and tetraethylorthosilicate (TEOS) were bought from Sigma-Aldrich Reagent (Shanghai, China). Chloroplatinic acid hexahydrate $\left(\mathrm{H}_{2} \mathrm{PtCl}_{6} \cdot 6 \mathrm{H}_{2} \mathrm{O}\right)$, 2-methylimidazole, all nitro compounds, and solvents were supplied by Sinopharm Chemical Reagent Co., Ltd (Shanghai, China).

\subsection{Catalyst Preparation}

Ordered mesoporous silica SBA-15 was obtained using P123 as a structure directing agent and TEOS as the silica source under acidic conditions according to the document [38]. CMK-3 was prepared using SBA- 15 as the template and sucrose as the carbon source, and then was carbonized at $900{ }^{\circ} \mathrm{C}$ for $6 \mathrm{~h}$ under nitrogen, as described by Ryoo et al. [39]. The silica template was removed using $5 \mathrm{wt} \%$ hydrofluoric acid aqueous solutions at room temperature. The CMK-3 product was obtained after filtering, washing, and drying. The N-CMK-3 was prepared by an impregnation method with the following steps: $6 \mathrm{~g}$ of CMK-3 and a certain amount of 2-methylimidazole were dissolved in $60 \mathrm{~mL}$ deionized water at room temperature; the amount of 2-methylimidazole was 1, 2, and $3 \mathrm{~g}$ in the synthesis of N-CMK-3-1, N-CMK-3-2, and N-CMK-3-3, respectively; then, the mixture was stirred at $60{ }^{\circ} \mathrm{C}$ and the water was vaporized slowly; and finally, the obtained solid was calcined in $\mathrm{N}_{2}$ atmosphere at $800{ }^{\circ} \mathrm{C}$ for $6 \mathrm{~h}$ with a heating rate of $2{ }^{\circ} \mathrm{C} \mathrm{min}-1$.

$\mathrm{Pt} / \mathrm{N}-\mathrm{CMK}-3-\mathrm{x}$ (x represents the amount of 2-methylimidazole with 1, 2, and $3 \mathrm{~g}$ ) catalyst with $2 \mathrm{wt} \%$ of Pt was synthesized by ultrasound-assisted traditional wetness impregnation method. In brief, $6 \mathrm{~g}$ of N-CMK-3-x powder and $6.2 \mathrm{~mL} \mathrm{H}_{2} \mathrm{PtCl}_{6} \cdot 6 \mathrm{H}_{2} \mathrm{O}$ aqueous solution $\left(0.1 \mathrm{~mol} \mathrm{~L}^{-1}\right)$ were mixed with deionized water $(60 \mathrm{~mL})$ to form a homogeneous suspension under ultrasound conditions. Then, the mixture was stirred at $40^{\circ} \mathrm{C}$ until water was evaporated. Finally, the obtained solid was calcined in a flow of 30 vol. $\% \mathrm{H}_{2}$ in $\mathrm{N}_{2}$ at $200{ }^{\circ} \mathrm{C}$ for $3 \mathrm{~h}$ with a ramp rate of $2{ }^{\circ} \mathrm{C} \mathrm{min}^{-1}$. For comparison, $\mathrm{Pt} / \mathrm{CMK}-3$ was prepared by the identical route.

\subsection{Catalyst Characterization}

Nitrogen adsorption analysis was carried out at liquid nitrogen temperature $\left(-196^{\circ} \mathrm{C}\right)$ by using an ASAP2020 analyzer (Norcross, GA, USA). Prior to measurement, samples were degassed at $200^{\circ} \mathrm{C}$ for $10 \mathrm{~h}$. The specific surface areas of the samples were calculated by the Brunauer-Emmett-Teller (BET) method. The pore volume was calculated at relative pressure $\mathrm{P} / \mathrm{P}_{0}$ of 0.991 . The pore size distribution plot was calculated using the Barrett-Joyner-Halenda (BJH) formula. The metal Pt loading amount of the catalysts was determined on ICP-AES (Waltham, MA, USA). The N content in the catalysts was measured by using the PerkinElmer $2400 \mathrm{CHN}$ elemental analyzer (Waltham, MA, USA). XRDpatterns were performed on a Rigaku D/MAX-2200 (Billerica, MA, USA) apparatus with a $\mathrm{Cu} K \alpha$ source $(40 \mathrm{kV}$, $40 \mathrm{~mA}$ ) at room temperature in the $2 \theta$ range of $10-90^{\circ}$. Transmission electron microscopy (TEM) and HAADF-STEM micrographs were obtained on a JEM-2010F (JEOL, Beijing, China) with an element energy-dispersive X-ray spectrometer operating at $200 \mathrm{kV}$. XPS of the catalysts were recorded with an ESCALAB 250xi spectrometer (Thermo Fisher Scientific, Waltham, USA) equipped with Al K $\alpha$ radiation source $(\mathrm{h} v=1486.6 \mathrm{eV})$. Binding energies of all elements were calibrated by $\mathrm{C} 1 \mathrm{~s}$ at $284.6 \mathrm{eV}$.

\subsection{Catalytic Reaction and Product Analyses}

The chemoselective hydrogenation of nitro aromatics was carried out in a $100 \mathrm{~mL}$ stainless-steel autoclave with a stirring controller. In a typical experiment, the autoclave was charged with $80 \mathrm{mmol}$ of nitro aromatics, $40 \mathrm{mg}$ of catalysts, and $20 \mathrm{~mL}$ of green solvent ethanol. Before starting the reaction, the reactor was flushed three times with $0.5 \mathrm{MPa}$ of hydrogen to remove the air, and then sealed tight and pressurized to $2 \mathrm{MPa} \mathrm{H}_{2}$. The stirring speed was kept at $800 \mathrm{rpm}$. Then the hydrogenation reaction was proceeded at $40{ }^{\circ} \mathrm{C}$ for a certain time. After the reactor was cooled to room temperature, 
the remaining $\mathrm{H}_{2}$ was carefully released. One hundred microliters of the mixture were isolated by filtration for further analysis.

Each reaction was repeated more than three times to reach the carbon balance of more than $98 \%$ and obtained the nitroarenes conversion with an error ascertained to be within $5 \%$. The qualitative and quantitative analyses of the products were done by gas chromatography (GC)-mass spectrometry (GC-MS, Shimadzu GCMS-QP 2010 Plus, Shanghai, China) and GC (Varian CP-3800, Palo Alto, California, USA) with n-decane as the internal standard.

For the recycling study, the hydrogenation reaction was performed in the same reaction conditions as mentioned above. The catalyst after each run was filtered, and washed several times with ethanol, and dried at $60{ }^{\circ} \mathrm{C}$. Then the recovered catalyst was directly used for the next run without any reactivation or purification. Considering the catalyst loss during the filtration, washing, and drying, the amount of catalyst changed throughout each cycle. However, the Pt/N-CMK-3-2/nitrobenzene/ethanol ratio was always kept the same as it was in the first cycle.

\section{Conclusions}

In summary, highly-dispersed $\mathrm{Pt}$ nanoparticles supported on nitrogen-modified CMK-3 mesoporous carbon were successfully synthesized by a facile two-step impregnation route. TEM results revealed that ultrafine $\mathrm{Pt}$ nanoparticles were uniformly dispersed on the $\mathrm{N}$-doped mesoporous carbon. The prepared $\mathrm{Pt} / \mathrm{N}-\mathrm{CMK}-3-2$ was found to exhibit much higher catalytic activity for the hydrogenation of various nitro aromatics as compared to the $\mathrm{Pt} / \mathrm{CMK}-3$ prepared without the incorporation of $\mathrm{N}$ species. The existence of $\mathrm{N}$ species in carbon matrix facilitated high metal dispersion and prevented the agglomeration of $\mathrm{Pt}$ nanoparticles, due to the interaction effect between $\mathrm{Pt}$ and $\mathrm{N}$ atoms, which resulted in high catalytic activity. In addition, the Pt/N-CMK-3-2 could completely transform various substituted nitro aromatics to the corresponding aromatic amines with excellent selectivity, even for the case of the halogenated nitrobenzene. The Pt/N-CMK-3-2 catalyst was highly stable and could be reused for the selective hydrogenation of nitrobenzene without obvious loss of catalytic performance.

Author Contributions: Y.S. analyzed the data and wrote the draft of the manuscript; Y.S. and X.L. performed the experiments; X.W. and C.Z. conceived and designed the experiments; X.Z. reviewed and edited the manuscript. All authors have read and agreed to the published version of the manuscript.

Funding: This research was funded by National Natural Science Foundation of China (U1860203, 51574164), CAS Interdisciplinary Innovation Team, and the Shanghai Engineering Research Center of Green Energy Chemical Engineering (No. 18DZ2254200).

Acknowledgments: This research was supported by National Natural Science Foundation of China (U1860203, 51574164), CAS Interdisciplinary Innovation Team, and the Shanghai Engineering Research Center of Green Energy Chemical Engineering (No. 18DZ2254200).

Conflicts of Interest: The authors declare no conflicts of interest.

\section{References}

1. Shokouhimehr, M. Magnetically separable and sustainable nanostructured catalysts for heterogeneous reduction of nitroaromatics. Catalysts 2015, 5, 534-560. [CrossRef]

2. Lu, H.; Geng, Z.; Li, J.; Zou, D.; Wu, Y.; Wu, Y. Metal-Free Reduction of Aromatic Nitro Compounds to Aromatic Amines with $\mathrm{B}_{2}$ pin $_{2}$ in Isopropanol. Org. Lett. 2016, 18, 2774-2776. [CrossRef] [PubMed]

3. Peng, W.C.; Chen, Y.; Li, X.Y. $\mathrm{MoS}_{2} /$ reduced graphene oxide hybrid with CdS nanoparticles as a visible light-Driven photocatalyst for the reduction of 4-Nitrophenol. J. Hazard. Mater. 2016, 309, 173-179. [CrossRef]

4. Deka, P.; Choudhury, R.; Deka, R.C.; Bharali, P. Influence of Ni on enhanced catalytic activity of $\mathrm{Cu} / \mathrm{Co}_{3} \mathrm{O}_{4}$ towards reduction of nitroaromatic compounds: Studies on the reduction kinetics. RSC Adv. 2016, 6, 71517-71528. [CrossRef]

5. Zhou, P.; Jiang, L.; Wang, F.; Deng, K.; Lv, K.; Zhang, Z. High performance of a cobalt-Nitrogen complex for the reduction and reductive coupling of nitro compounds into amines and their derivatives. Sci. Adv. 2017, 3, e1601945. [CrossRef] 
6. Tabatabaei Rezaei, S.J.; Khorramabadi, H.; Hesami, A.; Ramazani, A.; Amani, V.; Ahmadi, R. Chemoselective reduction of nitro and nitrile compounds with magnetic carbon nanotubes-supported $\mathrm{Pt}$ (II) catalyst under mild conditions. Ind. Eng. Chem. Res. 2017, 56, 12256-12266. [CrossRef]

7. Veerakumar, P.; Thanasekaran, P.; Lin, K.C.; Liu, S.B. Well-Dispersed rhenium nanoparticles on three-Dimensional carbon nanostructures: Efficient catalysts for the reduction of aromatic nitro compounds. J. Colloid Interface Sci. 2017, 506, 271-282. [CrossRef]

8. Nandi, D.; Siwal, S.; Choudhary, M.; Mallick, K. Carbon nitride supported palladium nanoparticles: An active system for the reduction of aromatic nitro-Compounds. Appl. Catal. A 2016, 523, 31-38. [CrossRef]

9. Formenti, D.; Ferretti, F.; Scharnagl, F.K.; Beller, M. Reduction of Nitro Compounds Using 3d-Non-Noble Metal Catalysts. Chem. Rev. 2019, 119, 2611-2680. [CrossRef]

10. Sudhakar, M.; Naresh, G.; Rambabu, G.; Anjaneyulu, C.; Padmasri, A.H.; Kantam, M.L.; Venugopal, A. Crude bio-Glycerol as a hydrogen source for the selective hydrogenation of aromatic nitro compounds over $\mathrm{Ru} / \mathrm{MgLaO}$ catalyst. Catal. Commun. 2016, 74, 91-94. [CrossRef]

11. Chen, Q.; Wang, M.; Zhang, C.; Ren, K.; Xin, Y.; Zhao, M.; Xing, E. Selectivity Control on Hydrogenation of Substituted Nitroarenes through End-On Adsorption of Reactants in Zeolite-Encapsulated Platinum Nanoparticles. Chem.-Asian J. 2018, 13, 2077-2084. [CrossRef] [PubMed]

12. Li, Z.; Liu, J.; Xia, C.; Li, F. Nitrogen-Functionalized ordered mesoporous carbons as multifunctional supports of ultrasmall Pd nanoparticles for hydrogenation of phenol. ACS Catal. 2013, 3, 2440-2448. [CrossRef]

13. Mao, H.; Peng, S.; Yu, H.; Chen, J.; Zhao, S.; Huo, F. Facile synthesis of highly stable heterogeneous catalysts by entrapping metal nanoparticles within mesoporous carbon. J. Mater. Chem. A 2014, 2, 5847-5851. [CrossRef]

14. Liu, W.; Yu, Y.; Du, J.; Jing, C. Reductive transformation of nitroaromatic compounds by Pd nanoparticles on nitrogen-Doped carbon (Pd@NC) biosynthesized using Pantoea sp. IMH. J. Hazard. Mater. 2019, 366, 338-345. [CrossRef]

15. Gao, D.; Li, S.; Wang, X.; Xi, L.; Lange, K.M.; Ma, X.; Lv, Y.; Yang, S.; Zhao, K.; Loussala, H.M.; et al. Ultrafine $\mathrm{PtRu}$ nanoparticles confined in hierarchically porous carbon derived from micro-Mesoporous zeolite for enhanced nitroarenes reduction performance. J. Catal. 2019, 370, 385-403. [CrossRef]

16. Xu, G.; Wei, H.; Ren, Y.; Yin, J.; Wang, A.; Zhang, T. Chemoselective hydrogenation of 3-Nitrostyrene over a $\mathrm{Pt} / \mathrm{FeO}_{x}$ pseudo-Single-Atom-Catalyst in $\mathrm{CO}_{2}$-Expanded liquids. Green Chem. 2016, 18, 1332-1338. [CrossRef]

17. Miao, H.; Hu, S.; Ma, K.; Sun, L.; Wu, F.; Wang, H.; Li, H. Synthesis of PtCo nanoflowers and its catalytic activity towards nitrobenzene hydrogenation. Catal. Commun. 2018, 109, 33-37. [CrossRef]

18. Sorribes, I.; Liu, L.; Corma, A. Nanolayered Co-Mo-S catalysts for the chemoselective hydrogenation of nitroarenes. ACS Catal. 2017, 7, 2698-2708. [CrossRef]

19. Yan, X.; Duan, P.; Zhang, F.; Li, H.; Zhang, H.; Zhao, M.; Zhang, X.; Xu, B.; Pennycook, S.J.; Guo, J. Stable single-Atom platinum catalyst trapped in carbon onion graphitic shells for improved chemoselective hydrogenation of nitroarenes. Carbon 2019, 143, 378-384. [CrossRef]

20. Guo, X.; Yu, C.; Yin, Z.; Sun, S.; Seto, C. Hydrodehalogenation of Polyhalogenated Aromatics Catalyzed by NiPd Nanoparticles Supported on Nitrogen-Doped Graphene. ChemSusChem 2018, 11, 1617-1620. [CrossRef]

21. Mane, G.P.; Talapaneni, S.N.; Anand, C.; Varghese, S.; Iwai, H.; Ji, Q.; Ariga, K.; Mori, T.; Vinu, A. Preparation of Highly Ordered Nitrogen-Containing Mesoporous Carbon from a Gelatin Biomolecule and its Excellent Sensing of Acetic Acid. Adv. Funct. Mater. 2012, 22, 3596-3604. [CrossRef]

22. Karimi, B.; Behzadnia, H.; Bostina, M.; Vali, H. A Nano-Fibrillated Mesoporous Carbon as an Effective Support for Palladium Nanoparticles in the Aerobic Oxidation of Alcohols "on Pure Water". Chem. Eur. J. 2012, 18, 8634-8640. [CrossRef] [PubMed]

23. Huang, H.; Tan, M.; Wang, X.; Zhang, M.; Guo, S.; Zou, X.; Lu, X. Synthesis of Mesoporous $\gamma$-Alumina-Supported Co-Based Catalysts and Their Catalytic Performance for Chemoselective Reduction of Nitroarenes. ACS Appl. Mater. Interfaces 2018, 10, 5413-5428. [CrossRef] [PubMed]

24. Zheng, L.; Dong, Y.; Chi, B.; Cui, Z.; Deng, Y.; Shi, X.; Du, L.; Liao, S. UIO-66-NH2-Derived Mesoporous Carbon Catalyst Co-Doped with Fe/N/S as Highly Efficient Cathode Catalyst for PEMFCs. Small 2019, 15, 1803520. [CrossRef]

25. Zhan, T.; Liu, W.; Teng, J.; Yue, C.; Li, D.; Wang, S.; Tan, H. Selective oxidation of glycerol to tartronic acid over $\mathrm{Pt} / \mathrm{N}-$ Doped mesoporous carbon with extra framework magnesium catalysts under base-Free conditions. Chem. Commun. 2019, 55, 2620-2623. [CrossRef] 
26. Liu, Z.; Dong, W.; Cheng, S.; Guo, S.; Shang, N.; Gao, S.; Feng, C.; Wang, C.; Wang, Z. Pd, Ag,-N-doped-MOF-C: An efficient catalyst for catalytic transfer hydrogenation of nitro-Compounds. Catal. Commun. 2017, 95, 50-53. [CrossRef]

27. Zhang, Y.; Cao, P.; Zhang, H.; Yin, G.; Zhao, J. Cobalt nanoparticles anchoring on nitrogen doped carbon with excellent performances for transfer hydrogenation of nitrocompounds to primary amines and N-Substituted formamides with formic acid. Catal. Commun. 2019, 129, 105747. [CrossRef]

28. Vakili, R.; Gibson, E.K.; Chansai, S.; Xu, S.; Al-Janabi, N.; Wells, P.P.; Hardacre, C.; Walton, A.; Fan, X. Understanding the CO oxidation on Pt nanoparticles supported on MOFs by operando XPS. ChemCatChem 2018, 10, 4238-4242. [CrossRef]

29. Banu, K.; Shimura, T. A novel electroless method for the deposition of single-Crystalline platinum nanoparticle films on an organic solid matrix in the presence of gold single crystals. New J. Chem. 2011, 35, 1503-1514. [CrossRef]

30. Wan, X.K.; Wu, H.B.; Guan, B.Y.; Luan, D.; Lou, X.W. Confining Sub-Nanometer Pt Clusters in Hollow Mesoporous Carbon Spheres for Boosting Hydrogen Evolution Activity. Adv. Mater. 2020, 32, 1901349. [CrossRef]

31. Duan, Y.; Song, T.; Dong, X.; Yang, Y. Enhanced catalytic performance of cobalt nanoparticles coated with a $\mathrm{N}, \mathrm{P}$-codoped carbon shell derived from biomass for transfer hydrogenation of functionalized nitroarenes. Green Chem. 2018, 20, 2821-2828. [CrossRef]

32. Zhang, F.; Zhao, C.; Chen, S.; Li, H.; Yang, H.; Zhang, X. In situ mosaic strategy generated Co-based N-doped mesoporous carbon for highly selective hydrogenation of nitroaromatics. J. Catal. 2017, 348, $212-222$. [CrossRef]

33. Li, X.; Zeng, C.; Jiang, J.; Ai, L. Magnetic cobalt nanoparticles embedded in hierarchically porous nitrogen-Doped carbon frameworks for highly efficient and well-Recyclable catalysis. J. Mater. Chem. A 2016, 4, 7476-7482. [CrossRef]

34. Zhang, M.; Dai, Q.; Zheng, H.; Chen, M.; Dai, L. Novel MOF-Derived Co@N-C bifunctional catalysts for highly efficient $\mathrm{Zn}$-Air batteries and water splitting. Adv. Mater. 2018, 30, 1705431. [CrossRef] [PubMed]

35. Tan, H.L.; Du, A.; Amal, R.; Ng, Y.H. Decorating platinum on nitrogen-Doped graphene sheets: Control of the platinum particle size distribution for improved photocatalytic $\mathrm{H}_{2}$ generation. Chem. Eng. Sci. 2019, 194, 85-93. [CrossRef]

36. Li, D.; Fang, H.; Yu, J.; Xu, M.; Li, T.; Wang, J. Porous carbon supported PtPd alloy nanoparticles derived from N-Heterocyclic carbene bimetal complex as efficient bifunctional electrocatalysts. Electrochim. Acta 2020, 337, 135855. [CrossRef]

37. Wang, Q.; Wang, X.; Chen, C.; Yang, X.; Huang, Y.; Cao, R. Defective Pt nanoparticles encapsulated in mesoporous metal-Organic frameworks for enhanced catalysis. Chem. Commun. 2018, 54, 8822-8825. [CrossRef]

38. Zhao, D.; Feng, J.; Huo, Q.; Melosh, N.; Fredrickson, G.H.; Chmelka, B.F.; Stucky, G.D. Triblock copolymer syntheses of mesoporous silica with periodic 50 to 300 angstrom pores. Science 1998, 279, 548-552. [CrossRef]

39. Jun, S.; Joo, S.H.; Ryoo, R.; Kruk, M.; Jaroniec, M.; Liu, Z.; Ohsuna, T.; Terasaki, O. Synthesis of new, nanoporous carbon with hexagonally ordered mesostructure. J. Am. Chem. Soc. 2000, 122, 10712-10713. [CrossRef]

(C) 2020 by the authors. Licensee MDPI, Basel, Switzerland. This article is an open access article distributed under the terms and conditions of the Creative Commons Attribution (CC BY) license (http://creativecommons.org/licenses/by/4.0/). 